\title{
RETRACTED ARTICLE: Early Pioneers of the Americas: The Role of the Olmecs in Urban Education and Social Studies Curriculum
}

\author{
Greg Wiggan $^{1} \mathbb{D} \cdot$ Annette Teasdell ${ }^{1} \cdot$ Marcia J. Watson-Vandiver ${ }^{2}$. \\ Sheikia Talley-Matthews ${ }^{1}$
}

Published online: 25 June 2020

(c) Springer Nature B.V. 2020

The Editor-in-Chief has retracted this article (Wiggan et al 2020) following concerns raised by readers. After post-publication peer-review, it was found that the theory that Olmecs were Black Africans on which the lesson plan is based is not substantiated according to current Mesoamerican archaeology and genetic evidence. The authors have been offered to submit a revised manuscript updated with information based on current knowledge for further peer review.

Author Greg Wiggan stated on behalf of all co-authors that they do not agree to this retraction.

Publisher's Note Springer Nature remains neutral with regard to jurisdictional claims in published maps and institutional affiliations.

Electronic supplementary material The online version of this article (https://doi.org/10.1007/s1125 6-020-00584-w) contains supplementary material, which is available to authorized users.

Greg Wiggan

gwiggan@uncc.edu

Annette Teasdell

ateasdel@uncc.edu

Marcia J. Watson-Vandiver

mjwatson@towson.edu

Sheikia Talley-Matthews

stalleymatthews@gmail.com

1 UNCC College of Education, University of North Carolina at Charlotte, Room 314, 9201

University City Blvd., Charlotte, NC 28223-0001, USA

2 Towson University, Towson, MD, USA

记 Springer 